\title{
Ultrasonographic determination of follicle development and resumption of ovarian activity in postpartum Bulgarian Murrah buffaloes during the breeding season
}

\author{
Stanimir Angelov Yotov, Anatoli Stefanov Atanasov \\ Dept. of Obstetrics, Reproduction and Reproductive Disorders, Faculty of Veterinary Medicine, Trakia University, Stara Zagora, Bulgaria
}

Email address:

stanrad@abv.bg (S. A. Yotov), a_stefanov@mail.bg (A. S. Atanasov)

\section{To cite this article:}

Stanimir Angelov Yotov, Anatoli Stefanov Atanasov. Ultrasonographic Determination of Follicle Development and Resumption of Ovarian Activity in Postpartum Bulgarian Murrah Buffaloes during the Breeding Season. Animal and Veterinary Sciences.

Vol. 1, No. 5, 2013, pp. 36-41. doi: 10.11648/j.avs.20130105.12

\begin{abstract}
The aim of the present study was to determine follicle development and resumption of ovarian activity in Bulgarian Murrah buffaloes by transrectal ultrasonographic monitoring of the ovaries during the first 50 days after after calving throughout the breeding season. The investigation included 18 clinically healthy Bulgarian Murrah buffaloes divided into two groups: Group I ( $\mathrm{n}=8$, primiparous buffaloes) and Group II ( $\mathrm{n}=10$, multiparous buffaloes). A transrectal ultrasonography was made at 3-day intervals between $1^{\text {st }}$ and the $50^{\text {th }}$ postpartum days. The evaluation of follicular development was based on the visualization of small, medium or large follicles. Ovulation was recorded when the first detected large follicle disappeared during the followed examinations and a corpus luteum in the same place was observed. After data processing, the mean diameter $(\mathrm{mm})$ of small, medium and large follicles was determined. The average intervals (days) from parturition to the first identification of medium, large follicles and corpus luteum were also estimated and cumulative percentage of animals in both groups, according to the ovarian structures, and the time of their detection was calculated. The obtained results showed presence of small follicles during the experimental period. The mean diameters of medium and large follicles in multiparous animals were greater $(\mathrm{P}<0.05)$ than respective sizes in primiparous animals. The mean interval between calving and first ovulation trended to be shorter in multiparous in comparison with primiparous buffaloes. On postpartum day 46 cumulative percentage of multiparous animals with detected corpus luteum was higher $(\mathrm{P}<0.05)$ than estimated in primiparous animals. In conclusion, the follicular growth between clinically healthy primiparous and multiparous Bulgarian Murrah buffaloes during the first fifty days after calving throughout breeding season was different. The faster development of ovulatory follicles followed by ovulation and corpus luteum formation in multiparous than in primiparous bufaloes indicated an earlier resumption of the ovarian activity after calving. The obtained data could be used in development of different schedules for reproductive optimization in dairy buffaloes.
\end{abstract}

Keywords: Buffaloes, Postpartum Ovarian Activity, Ultrasound

\section{Introduction}

The resumption of ovarian activity has been described as a mean factor contributing to reduction of the postpartum anoestrus and effective reproductive performance in the buffalo species $[1,2,3]$. A distinguishing feature in postpartum buffaloes compared to cows is the strong influence of light-darkness shift over the months, climatic conditions and reproductive maturity of the animals on the restoration of the ovarian activity with a clinical estrus expression $[4,5]$.

A comprehension of the pattern of follicle development in postpartum buffaloes could provide some additional insights and improve protocols for estrus synchronization and induction of ovulation for successive artificial insemination [6]. The rectal palpation [7, 8] and ultrasound [9-11] have been used extensively to examine ovarian function in buffaloes under field condition, but the diagnostic value of both methods is however variable [12]. Rectal palpation is a routine technique for investigation of ovarian structures, but it does not provide adequate information about ovarian function and its accuracy is lower than that of other diagnostic methods [13-15]. Size of the ovaries, degree of relaxation of the rectal wall, body condition score and the experience of the operator are limiting factors for calculation of small follicles size and number of the small follicles [16, 
17]. A significant problem with corpus luteum identification by rectal examination during the early postpartum period was reported by different authors [10,13].

The introduction of transrectal ultrasonography in buffalo reproduction increased the potential for real-time detection of changes occurring in ovaries during the late pregnancy and the postpartum period $[15,18,19]$. One of the correct criteria for resumption of the postpartum ovarian activity and successful ovulation is detection of a corpus luteum, different from the gestational one [20, 21]. Reports on the relationship between parity and interval to first postpartum ovulation are few with wide discrepancies. Data obtained by rectal palpation evidenced that the interval to start of ovarian cyclic activity in milked dairy buffaloes, possibly referred to their reproductive potential [12]. Only one study [6] reported detailed data from ultrasonographic monitoring of postpartum ovarian follicular dynamics in primiparous and multiparous animals, but it was done in Mediterranean Italian buffaloes during the non-breeding season.

Despite performed reports, a clear standpoint for the influence of the parity on the follicular development and resumption of ovarian activity in postpartum dairy type buffaloes during the breeding season is absent. The information connected with the first ovulatory follicles size and resumption of ovarian activity after calving among different buffalo breeds is rather controversial. Most of the results have been obtained by a single rectal examination or ultrasonography in mixed (primiparous and multiparous buffaloes) groups. The aim of the present study was to determine follicle development and resumption of ovarian activity in Bulgarian Murrah buffaloes by transrectal ultrasonographic monitoring of the ovaries during the first 50 days after after calving throughout the breeding season.

\section{Material and Methods}

The study was conducted with 18 clinically healthy Bulgarian Murrah buffaloes separated into two groups group I primiparous $(\mathrm{n}=8,460-480 \mathrm{~kg}$ body weight, $3.4 \pm 0.2$ years old) and group II multiparous ( $\mathrm{n}=10 ; 560-600 \mathrm{~kg}$ body weight, $6.8 \pm 0.7$ years old). The animals were with normal parturition, having given birth to a single calf, without clinical signs of endometritis during the experimental period. Calves were separated from dams 12 hours after the calving and fed a milk replacer, according to farm management. The average daily milk yield in primiparous and multiparous buffaloes was $4.6 \pm 0.31$ and $5.9 \pm 0.61$, respectively, with milking twice daily - morning and evening. The animals were reared in a private farm located at latitude of $42.183 \mathrm{~N}$, longitude $25.567 \mathrm{E}$. The daily ration included concentrate, hay, straw, 7 hours controlled grazing and water ad libitum. The study was carried out from September to November (breeding season). A transrectal ultrasonography was made at 3-day intervals between $1^{\text {st }}$ and the $50^{\text {th }}$ postpartum days, early in the morning, immediately after milking and before pasture by the same operator. An ultrasound SonoScape A5
Vet (SonoScape Co. LTD, Shenzhen, China) and multifrequency (7-12 MHz) linear transducer were used. The evaluation of follicular development was based on the visualization of small, medium or large follicles, measured using the in-built scale provided with the ultrasound. Ovulation was recorded when the first detected large follicle disappeared during the followed examinations and a corpus luteum in the same place was observed [22]. Ultrasonographies in each animal continued until detection of a corpus luteum into one of both ovaries. After data processing a mean diameter $(\mathrm{mm})$ of small, medium and large follicles and the average intervals (days) from parturition to the first identification of medium and large follicles and corpus luteum were estimated. The cumulative percentages of animals from both groups according to the ovarian structures and the time of their detection were calculated. Statistical analysis was performed with the Stat-Soft 1984-2000 Inc. statistical software (Copyright ( 1990-1995 Microsoft. Corp.) by means a non-parametric analysis for comparison of two means and proportions, using Student's t-criterion. Differences were considered significant in $p$-values $\leq 0.05$.

\section{Results}

The ultrasonography showed presence of small follicles into the ovaries of all animals during the experimental period (Fig. 1a), whereas visualisation of medium and large follicles started later (Fig. 1b,c). According to accepted criteria (Fig. 1d), ovulation was recorded for six primiparous and nine multiparous buffaloes.

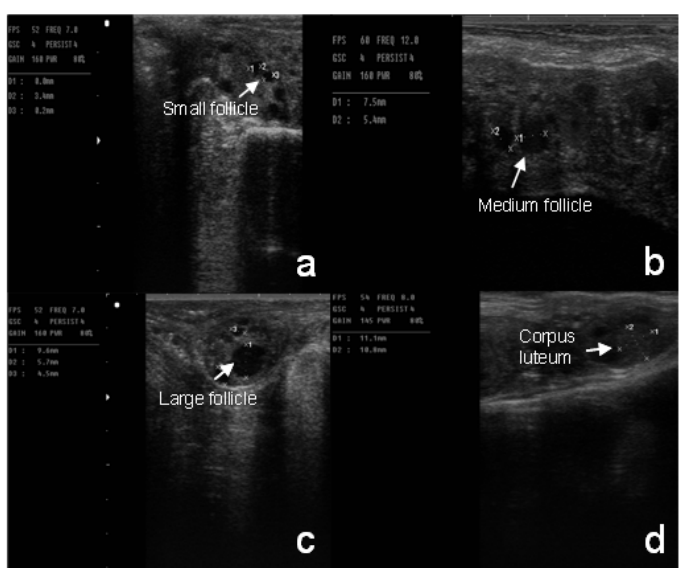

Figure 1. Ultrasonographic appearance of different ovarian structures in Bulgarian Murrah buffaloes: $a$-small follicle; $b$ - medium follicle; $\quad c$ large follicle; $d$-corpus luteum.

Mean diameters of small follicles in buffaloes from the first and the second group did not differ significantly $(\mathrm{P}=$ 0.07; Table 1). The sizes of medium and large follicles in multiparous animals were greater $(\mathrm{P}<0.05)$ than those calculated in primiparous animals. The intervals between calving and the first identification of medium follicle, large follicle and corpus luteum for the group I were numerically shorter in comparison with those for group II, but were 
statistically similar $(\mathrm{P}>0.05)$. The significant differences $(\mathrm{P}<0.05)$ between mean diameters of the first large and medium follicles in both groups and data for the intervals from calving to their first identification were evidence for the earlier resumption of ovarian activity in multiparous buffaloes.

Table 1. Mean diameter of the different follicles and interval between partus and firs identification of medium follicle, large follicle and corpus luteum in Bulgarian Murrah buffaloes.

\begin{tabular}{llll}
\hline $\begin{array}{l}\text { Groups } \\
\text { Parameters }\end{array}$ & & $\begin{array}{l}\text { I (n=8) } \\
\text { (Mean } \pm \text { SD) }\end{array}$ & $\begin{array}{l}\text { II (n=10) } \\
\text { (Mean } \pm \text { SD) }\end{array}$ \\
\hline Follicular diameter $(\mathrm{mm})$ & & $4.56 \pm 0.46$ & $4.80 \pm 0.62$ \\
Small follicles & & $6.42 \pm 0.40^{\mathrm{a}}$ & $7.98 \pm 0.94^{\mathrm{b}}$ \\
Medium follicles & & $10.12 \pm 0.72^{\mathrm{a}}$ & $13.1 \pm 0.96^{\mathrm{b}}$ \\
Large follicles & & $15.4 \pm 3.91$ & $11.67 \pm 4.77$ \\
Interval between partus and first & identification of medium follicle (days) & $19.0 \pm 4.74$ & $16.33 \pm 4.09$ \\
Interval between partus and first & identification of large follicle (days) & $38.6 \pm 12.46$ & $31.00 \pm 12.10$ \\
Interval between partus and first & identification of corpus luteum (days) & & \\
\hline
\end{tabular}

Values with different superscripts within a row differ significantly at $\mathrm{P}<0.05$.

The data related to cumulative percentage of buffaloes bearing small, medium, large follicles or corpus luteum in the ovaries are presented in Fig. 2. Small follicles were observed in $100 \%$ of animals in both groups between 1st and the 50th postpartum day. In $12.5 \%$ of primiparous buffaloes, a medium follicle was first detected at postpartum day 10 , whereas in $30 \%$ of multiparous animals its determination was at day 7 after calving. Between postpartum days 13 to 19 , cumulative percentages of buffaloes with medium follicles in group II increased from $80 \%$ to $100 \%$, while in the group I ranged from $25 \%$ to $62.5 \%$. The differences between obtained values of both groups were significant at $\mathrm{P}<0.05$. Initially, a large follicle was demonstrated in $20 \%$ of multiparous buffaloes at postpartum day 10 , whereas in primiparous animal only one buffalo had a large follicle up to postpartum day 13. Moreover, the cumulative percentage of animals with first detected large follicle showed that follicles $\geq 9 \mathrm{~mm}$ can be detected in $100 \%$ of multiparous animals at postpartum day 25 , whereas in primiparous buffaloes that was possible latter day 31 postpartum. The registered differences $(\mathrm{P}<0.05)$ between the groups during postpartum days 19-25 were in accordance with the above mentioned facts and indicated faster follicular development in II group.

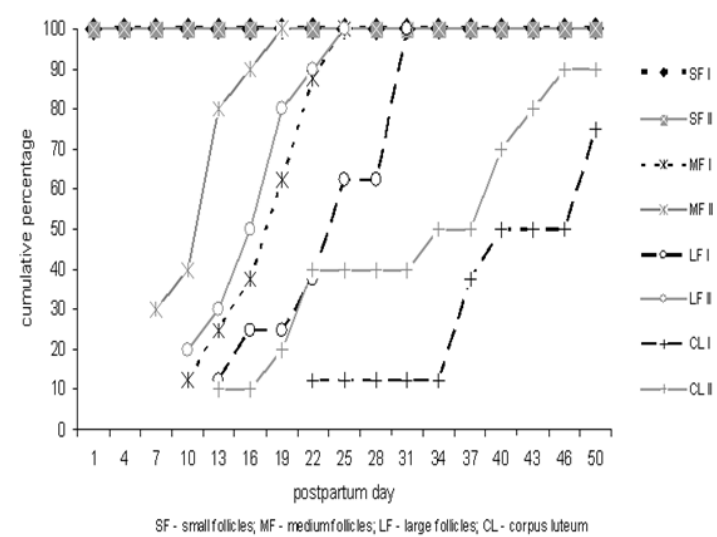

Figure 2. Cumulative percentages of primiparous (I) and multiparous (II) buffaloes according to ovarian structures identification and postpartum day.
For the first time, a corpus luteum was observed earlier in multiparous than in primiparous buffaloes (postpartum day 13 vs. 22). In the second group there was a trend to rapid increase in the cumulative percentage of animals with detected corpus luteum after ovulation. On Day 46 postpartum, the animals bearing a CL in the second group $(90 \%)$ were significantly $(\mathrm{P}<0.05)$ greater than those $(50 \%)$ in the first group. Until the end of experiment, $25 \%$ primiparous and $10 \%$ multiparous buffaloes did not ovulate, despite of determination of follicles with ovulatory size into the ovaries. A total value of buffaloes with missed ovulation was $16.6 \%$.

\section{Discussion}

The ultrasonographic monitoring of follicle development and corpus luteum formation contributes to the correct detection of the time for postpartum resumption of ovarian activity in buffaloes [11, 15]. According to Lohan et al. [23] on day 6 postpartum the average number of small and medium follicles was $8.10 \pm 5.67$ and $1.00 \pm 0.00$, respectively. Mean size of the medium follicles varied between $4.37 \pm 0.28$ $\mathrm{mm}$ and $4.05 \pm 0.05 \mathrm{~mm}$ and large size follicles appeared between 10 to 30 days postpartum. Presicce et al. [6] observed a gradual increase of follicles $\geq 3 \mathrm{~mm}$ during the first two weeks after calving in Mediterranean Italian buffaloes. In most Thai Swamp buffaloes the onset of ovarian cyclicity was manifested by development of waves of follicles $\geq 5 \mathrm{~mm}$ as the first dominant follicle reached $10.80 \pm 0.20 \mathrm{~mm}$ in diameter [22]. After its atresia a new dominant follicle $(12.92 \pm 0.96 \mathrm{~mm})$ that ovulated or regressed was determined. Usmani et al. [7] detected follicles $>8 \mathrm{~mm}$ in Nili Ravi buffaloes at postpartum days $21.4 \pm 0.8$ and reported to first registration in buffaloes during the second lactation and last in animals during the first lactation.

The obtained results showed persisting of small follicles into the ovaries of all animals during the first 50 postpartum days that coincided with the data reported by Usmani et al. [7]. 
The mean small follicle diameters were similar in primiparous and multiparous Bulgarian Murrah buffaloes and were close to the size of small follicles calculated by Lohan et al. [23]. The significantly $(\mathrm{P}<0.05)$ greater size (7.98 $\pm 0.94 \mathrm{~mm})$ of medium follicles in animals from group II than those $(6.42 \pm 0.40 \mathrm{~mm})$ registered in group I indicated earlier start of follicular wave or faster growth of the follicles in multiparous animals. Yindee et al. [22] also reported that postpartum follicular dynamics in multiparous buffaloes was characterized by the emergence of waves of follicles $\geq 5 \mathrm{~mm}$, whereas other research [23] showed resumption of ovarian activity when the follicular diameter was $>8.5 \mathrm{~mm}$. The tendency for a shorter interval between calving and the first identification of a medium follicle in animals with more than one parturition, confirms the hypothesis for differences with regard to the resumption of ovarian activity between primiparous and multiparous dairy buffaloes during the breeding season. Another evidence was the significant differences $(\mathrm{P}<0.05)$ between cumulative percentages of animals with first detected medium follicle between days 13 to 19 after calving. A different standpoint was presented by Presicce et al. [6]. They established a similarity in the majority of parameters associated with postpartum ovarian activity and follicular dynamics in primiparous and multiparous Mediterranean Italian buffaloes. Their experiment was however performed with a different buffalo breed during the non-breeding season (with increasing daylight hours), while our study was done during the breeding season. The overview of Terzano et al. [24] on reproductive endocrine aspects in buffaloes showed that these animals are polyoestrous, but the photoperiod plays major role on their reproduction, in particular on postpartum resumption of the ovarian activity. A probable reason for the later start of follicular activity in primiparous buffaloes could be the stress during the parturition and/or slower decrease of blood progesterone levels after that. In this aspect, Zicarelli [4] reported anovulatory conditions caused by the stress of first lactation or possibly bad management in the course of first pregnancy. Presicce et al. [6] determined progesterone values of $0.19 \pm 0.0 \mathrm{ng} / \mathrm{mL}$ and $0.17 \pm 0.0 \mathrm{ng} / \mathrm{mL}$ in primiparous and multiparous buffaloes, respectively within $24 \mathrm{~h}$ from calving and speculated to a different metabolism of progesterone between primiparous and multiparous buffaloes. Future research related to investigation of stress indicators and steroid hormone levels in the earliest postpartum will clarify this question.

The information about the relationship between parity and interval up to first postpartum ovulation is insufficient and sometimes conflicting. Based on the results by rectal palpation, the interval between parturition and first ovulation ranged from $28 \pm 1$ days [25], 59 \pm 5 days [26] to $109 \pm 10$ days [27]. An absence of significant impact of parity on the time for first postpartum ovulation was reported by El-Fouly et al. [28], while a shorter period in multiparous than in primiparous buffaloes was determined by Barkawi [29]. After ultrasonography in primiparous Mediterranean Italian buffaloes, the calving to first postpartum ovulation interval was $25.5 \pm 6.9$ days (range 16-46) and in multiparous buffaloes was $15.5 \pm 1.3$ days (range $8-20$ ). The maximum diameter of the first ovulatory follicles was $13.5 \pm 0.8 \mathrm{~mm}$ and $14.1 \pm 0.4 \mathrm{~mm}$ for the first and the second animal class, respectively [6]. However, other study [22] reported to first ovulation in multiparous Thai swamp buffaloes at $39.8 \pm 3.38$ postpartum days with mean diameter of the first ovulatory follicles $13.5 \pm 0.52 \mathrm{~mm}$. According to El-Wishy [12] the interval to first ovulation can be included among the traits for selection of breeding buffaloes for improving their reproductive capacity.

Notwithstanding the insignificant differences between the primiparous and multiparous Bulgarian Murrah buffaloes there was a trend for reduction of the time between parturition and the initial identification of a corpus luteum in the second group. The greater cumulative percentage $(\mathrm{P}<0.05)$ of multiparous buffaloes with corpora lutea on postpartum day 46 confirmed this and could be explained by rapid increase (from $10 \%$ to $90 \%$ ) of ovulated animals after day 13 postpartum. In primiparous buffaloes this process was slower (from $12.5 \%$ to $50 \%$ ) and started by day 34 after calving. Presicce et al. [6] proved the first ovulation at postpartum earlier (postpartum day 8), but the average interval for its detection in primiparous and multiparous buffaloes was shorter than that obtained in current survey. By using the same method, Yindee et al. [22] ascertained an interval between parturition and first ovulation (39.8 \pm 3.38 days), comparable to our results $(31.00 \pm 12.10$ and $38.6 \pm 12.46$ days). However, the first ovulatory follicles $(12.92 \pm 0.96 \mathrm{~mm})$ was greater of size than the one $(10.12 \pm 0.72 \mathrm{~mm})$ registered in primiparous animals in this study.

We consider that discrepancies between above mentioned and presented results could mainly depend on the parity and the buffalo breed. The first authors used Mediterranean Italian buffaloes during the non-breeding season and the second research team included in their experiments only multiparous buffaloes (range 2-7 parities) from Thai Swamp breed. In agreement with our data Gimenes et al. [30] stated that follicles in buffalo heifers acquired ovulatory capacity when they reached $8.5 \mathrm{~mm}$ in diameter. Derar et al. [31] also registered a smaller size of ovulatory follicles $(10.2 \pm 0.9 \mathrm{~mm})$ in younger than older buffaloes.

An absence of corpus luteum until the end of experiment in $25 \%$ and $10 \%$ of cases in group I and group II, respectively, supported the hypothesis that resumption of ovarian activity in younger animals required more time. Possibly most of the energy in younger buffaloes was used for body condition and milk production maintenance that had a negative effect on follicle development and ovulation. In dairy buffaloes, inadequate energy balance was an important cause of a low follicular growth, lack of ovulation or impaired development of the CL and delayed postpartum resumption of ovarian activity [32]. The undetected ovulation in $16.6 \%$ of all animals, despite the presence of follicles with ovulatory size could be due to the lack of ovulation and regression of the dominant follicles. Opsomer 
[33] determined that not only the follicular size was responsible for successful ovulation, but the most important factor was estrogens production. According to this research, an altered feedback mechanism of oestrogens on the hypo-thalamus-pituitary axis can result in an aberrant $\mathrm{GnRH} / \mathrm{LH}$ release and lack of ovulation.

In conclusion, the follicular growth between clinically healthy primiparous and multiparous Bulgarian Murrah buffaloes during the first fifty days after calving throughout breeding season was different. The faster development of ovulatory follicles followed by ovulation and corpus luteum formation in multiparous than in primiparous bufaloes indicated an earlier resumption of the ovarian activity after calving. The obtained data could be used in development of different schedules for reproductive optimization in dairy buffaloes.

\section{Acknowledgements}

Research conducted by the authors was supported by Research Grant \# 2012-10, Trakia University, Stara Zagora, Bulgaria. The authors gratefully acknowledge the help of all people from Dimitrievo farm during the experiment.

\section{References}

[1] Khasatiya CT, Kavani FS, Dhami AJ, Derashri HJ, Panchal, MT, Desai PM. Studies on puerperal events and reproductive efficiency following hormone therapy at day 42 postpartum in surti buffaloes. Int J Agri Biol 2006; 8: 132-137.

[2] El-Wishy AB. The postpartum buffalo I. Endocrinological changes and uterine involution. Anim Reprod Sci 2007; 97: 201-215.

[3] Ahmed WM, El-Khadrawy HH, Abd El-Hameed RR, Amer HA. Applied investigations on ovarian inactivity in buffalo hifers. Int J Acad Res 2010; 2: 26-32.

[4] Zicarelli L. Reproductive seasonality in buffalo. Third course on biotechnology of reproduction in buffaloes. In Suppl 4/98, Bubalus bubalis, Caserta, Italy, 1997: 29-52.

[5] Perera BMAO. Reproductive cycles of buffalo. Anim Reprod Sci 2011; 124:194-199.

[6] Presicce GA, Bella A, Terzano GM, De Santis G, Senatore EM. Postpartum ovarian follicular dynamics in primiparous and pluriparous Mediterranean Italian buffaloes (Bubalus bubalis). Theriogenology 2005; 63: 1430-1439.

[7] Usmani RH, Ullah N, Shah SK. A note on the effect of suckling stimulus on uterine involution, postpartum ovarian activity and fertility in Nili Ravi buffaloes. Anim Prod 1985; 41:119-122.

[8] Tiwari SR, Pathak MM Influence of suckling on postpartum reproductive performance of Surti buffaloes. Buffalo J 1995; 11: 213-217.

[9] Dahiya V, Lohan JS, Saini MS, Kaker ML, Malik RK. Ultrasonographic assessment of ovarian changes in anestrous buffaloes treated with norgestomet. Indian J Anim Sci 2003; 73:1033-1036.
[10] Honparkhe M, Gandotra VK, Nanda AS. Ultrasonographic Measurements in comparison with the rectal palpation and echotexture of reproductive organs of buffaloes (Bubalus bubalis) during different stages of the estrous cycle. Aust $\mathbf{J}$ Anim Sci 2004; 17: 919-923.

[11] Terzano GM. Ultrasonography and Reproduction in Buffalo. J Buffalo Sci 2012; 1: 163-173.

[12] El-Wishy AB. The postpartum buffalo: II. Acyclicity and anestrus. Anim Reprod Sci 2007; 97: 216-36.

[13] Usmani RH, Ahmed M, Inskeep EK, Dailey RA, Lewis PE, Lewis GS. Uterine involution and postpartum ovarian activity in Nili Ravi buffaloes. Theriogenology 1985; 24: 435-445.

[14] Younis M, Abass HI, Essawy GS, Otteifa AM, Essawy SA, Fadaly M Diagnostic laboratory tests to verify ovulation occurrence with evaluation of accuracy of rectal palpation in buffaloes. Egyptian J Anim Prod 1994; 31: 443-451.

[15] Rahman MS, Shohag AS, Kamal MM, Parveen N, Shamsuddin M. Application of ultrasonography to investigate postpartum anestrus in water buffaloes. Reprod Dev Biol 2012; 36: 103-108.

[16] El-Wishy AB, Ghoneim IM. Ovarian function in buffalo cows with special reference to accuracy of rectal palpation. Reprod Domest Anim 1995; 30: 39-41.

[17] Hanzen CH, Pieterse M, Scenczi O, Drost M. Relative accuracy of the identification of ovarian structures in the cow by ultrasonography and palpation per rectum. Br Vet J 2000; 159: 161-170.

[18] Baruselli PS, Mucciolo R, Visintin GA, Viana VC, Arruda RP, Madureira EH. Ovarian follicular dynamics during the estrous cycle in buffalo (Bubalus bubalis). Theriogenology 1997; 47: 1531-1547.

[19] Khan MI-R, Rana MA, Ahmad N. Ultrasonic monitoring of follicles and corpora lutea during synchronization in summer anoestrus Nili-Ravi buffaloes and theirs ubsequent superovulatory response. Pakistan Vet J 2005; 25: 82-86.

[20] Usmani RH, Ahmed N, Shafiq P, Mirza MA. Effect of subclinical uterine infection on cervical and uterine involution, estrous activity and fertility in postpartum buffaloes. Theriogenology 2001; 55: 563-571.

[21] Martin AD, Lystad ML, Reksen O, Ropstad E, Waldmann A, Nafstad O, et al. Assessment of progesterone profiles and postpartum onset of luteal activity in spring calving Hereford beef suckler cattle. Acta Vet Scand 2010; 52: 42-42.

[22] Yindee M, Techakumphu M, Lohachit C, Sirivaidyapong S, $\mathrm{Na}-$ Chiangmai A, Rodriguez-Martinez $\mathrm{H}$ et al. Follicular dynamics and oestrous detection in Thai Postpartum Swamp buffaloes (Bubalus bubalis) Reprod Dom Anim 2011; 46:e91-e96.

[23] Lohan IS, Malik RK, Kaker ML. Uterine involution and ovarian follicular growth during early postpartum period of Murrah buffaloes. Asian-Aust J Anim Sci 2004; 17:313-316.

[24] Terzano GM, Barile VL, Borghese A. Overview on reproductive endocrine aspects in buffalo. J Buffalo Sci 2012; 1: $126-138$.

[25] El-Shafie MM, Borady AMA, Mourad HM, Khattab RM. 
Physiological and seasonal factors affecting reproductive performance of Egyptian buffalo heifers. Egypt J Anim Prod $1983 ; 23: 1-14$

[26] Qureshi MS, Samad HA, Anmad N, Habib G, Anjum AD, Siddiqui MM. Reproductive performance of dairy buffaloes under periurban commercial farming in NWFP, Pakistan. Pak Vet J 1998; 18: 197-201.

[27] Ali MA, El-Sheikh AS. Postpartum ovulation in a herd of Egyptian buffaloes. Indian J Anim Sci 1983; 53: 485-487.

[28] El-Fouly MA, Kotby EA, El-Sobhy HE. Postpartum ovarian activity in suckled and milked buffaloes. Theriogenology 1976; 5: 69-81.

[29] Barkawi AH. Postpartum reproductive pattern of suckling and non-suckling Egyptian buffaloes. Egypt J Anim Prod 1993; 30: 129-142.
[30] Gimenes LU, Carvalho NAT, SáFilho MF, Vannucci FS, Torres-Júnior JRS, Ayres $\mathrm{H}$ et al. Ultrasonographic and endocrine aspects of follicle deviation, and acquisition of ovulatory capacity in buffalo (Bubalus bubalis) heifers. Anim Reprod Sci 2011; 123: 175-179.

[31] Derar R, Hussein HA, Fahmy S, El-Sherry TM, Megahed G. The effect of parity on the efficacy of an ovulation synchronization (Ovsynch) protocol in buffalo (Bubalus bubalis). Anim Reprod 2012; 9:52-60.

[32] Qureshi MS. Nutritional and management support to reproduction in dairy buffaloes under tropical conditions. Pakistan J Zool Suppl 2009; 9: 895-909.

[33] Opsomer G. Cystic ovarian follicles in dairy cattle. Reproduction management bulletin of partners and reproduction 2009; 6:1-6. 